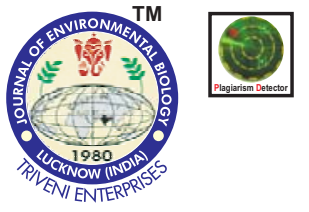

\title{
Pheno-physiological evaluation of finger millet germplasm of Central Himalayan Region
}

Authors Info

\author{
A.K. Trivedi ${ }^{1 *}$, S.K. Verma ${ }^{1}$ \\ and R.K. Tyagi ${ }^{2}$ \\ ${ }^{1}$ ICAR - Central Institute for \\ Subtropical Horticulture \\ Rehmankhera, Kakori, \\ Lucknow - 226 101, India \\ ${ }^{2}$ ICAR - National Bureau of Plant \\ Genetic Resources Pusa Campus, \\ New Delhi - 110 012, India
}

*Corresponding Author Email : ajayakumartrivedi@gmail.com

Key words

Finger millet Germplasm Genetic diversity

Pheno-physiological traits

\section{Publication Info}

Paper received : 03.11.2016

Revised received: 17.03 .2017

Re-revised received : 30.06 .2017

Accepted: 05.08.2017

\section{Abstract}

Aim : Millets play a key role in the food security of Central Himalayan Region. Evaluation of finger millet [Eleusine coracana $(\mathrm{L})$ Gaertn] genetic diversity is yet lacking in this region. Hence, the present study was conducted with the aim to explore, collect and evaluate the genetic diversity of finger millet in order to identify trait specific germplasm for crop improvement.

Methodology : Exploration expeditions were conducted in the finger millet growing areas of Central Himalayan Region i.e., Uttarakhand State of India. A total of 314 accessions were collected from altitudinal range of 225-2250 m asl. Collected germplasm was grown at one place and evaluated for various phenophysiological traits.

Results : Ample diversity was found in pheno-physiological traits viz., flag leaf length $(17.91-97.92 \mathrm{~cm})$, fag leaf width $(0.83-1.23)$, flag leaf angle $\left(19-53^{\circ}\right)$, peduncle length $(9.02-45.43 \mathrm{~cm})$, plant height $(71.71-140.30 \mathrm{~cm})$, days to $50 \%$ flowering $(66.00-98.00)$, days to $80 \%$ maturity $(117.00-147.00)$, days to harvesting $(141-149)$, ear head length $(4.16-14.61 \mathrm{~cm})$ and 1000 seed weight $(1.01-4.71 \mathrm{~g})$. In addition, these accessions were evaluated for variability in total chlorophyll (1.02 - $6.90 \mathrm{mg} . \mathrm{g}^{-1}$ fresh weight), carotenoids ( $0.87-4.33$ $\mathrm{mg} \cdot \mathrm{g}^{-1}$ fresh weight) content and lipid peroxidation $(0.55-7.42 \mathrm{n}$ mol MDA formed. $\mathrm{mg}^{-1}$ protein. $\mathrm{hr}^{-1}$ ). Seeds of collected germplasm had wide variability in nutritional traits viz., carbohydrate $(72.56-79.22 \%)$, fat $(1.31-2.52 \%)$ and protein (5.66 -

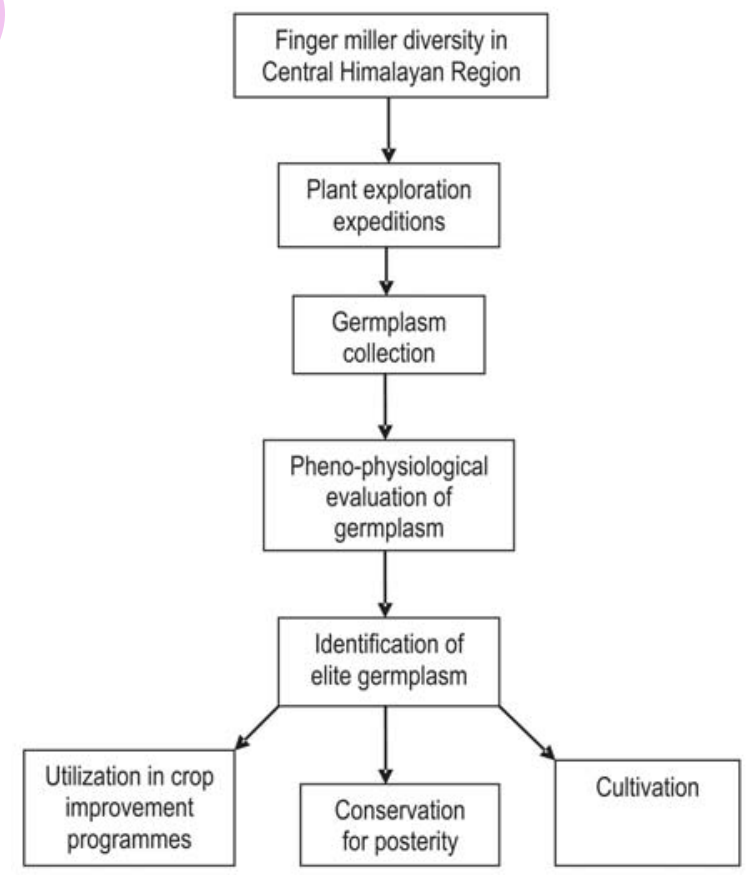
$12.96 \%$ ) content. Principal components responsible for variability were identified.

Interpretation : Central Himalayan Region has been found to have enormous diversity of finger millet. Collected germplasm had remarkable ability to withstand varying weather conditions and resistance to environmental/ abiotic stresses. Substantial diversity noticed in different traits might be utilized for crop improvement to develop nutritionally rich and abiotic/ biotic stress tolerant varieties. 


\section{Introduction}

Food production in India has increased significantly in the past few decades. However, for burgeoning population food and nutrition security for days to come is still a serious concern which is to be achieved in a sustainable manner. Improvement in food production depends largely on available genetic diversity of food crops. The genetic diversity of crops is a fundamental resource for the continued improvement of varieties needed to cope with changes. To adapt the changes in the environmental conditions genetic diversity contributes to the different dimensions of food security viz., food availability, access to food, food utilization and stability. Phenological traits, i.e., pheno-phases of growth and development, have great impact on the adaptation of plants to the existing environment, all with the aim of achieving a maximum productivity (Richards, 1991). Selection of one trait can reduce the chance for successful selection for some other trait, due to a competitive relationship towards the same source of nutrients. However, combination of traits in various ways contribute to the improvement of yields can result in a maximum gain of each trait individually (Quarrie et al., 1999). In developing higher-yielding crops, 'physiological phenotyping' of specific traits will be useful in developing higher-yielding cultivars (Tardieu and Tuberosa, 2010).

Finger millet [Eleusine coracana $(L)$ Gaertn] is a fast growing cereal crop that reaches maturity within 3 to 6 months (Dida and Devos, 2006). It is commonly found at altitudes between 1000 to $2000 \mathrm{~m}$ asl in eastern and southern Africa and up to 2500 to $3000 \mathrm{~m}$ asl in the Himalayas (FAO, 2012; Dida and Devos, 2006). It grows best at an average temperature of $23^{\circ} \mathrm{C}$ but can withstand cooler and hotter conditions (FAO, 2012). Eleusine species occupy diverse habitats, ranging from open, dry places to forests under-covers. Finger millet is extensively grown in Africa and India through selection of genotypes adapted to different agro ecological conditions (Werth et al., 1994; Das et al., 2007). Natural selection may play a significant role in finger millet evolution (Hilu, 1995). It is one of the ancient millets in India (2300 $\mathrm{BC})$. Presently, India is a major finger millet producing country in the world. Finger millet is important minor millet grown in more than 25 countries and accounts for $12 \%$ of the global millet area (ICRISAT, 2008). It has been recognized as a highly nutritious food for weak and immuno-compromised people (Takan et al., 2012). It survives under severe water-deficit and other abiotic stresses and shows remarkable recovery on alleviation of stress (Govind et al., 2009). Although, this crop is adapted to resist stress, little is known about traits responsible for stress tolerance. Furthermore, meagre data is on record regarding stress and its impact on chlorophyll, carotenoids content as well as lipid peroxidation in finger millet, which are useful traits for screening germplasm for stress tolerance. Considerable genetic diversity of finger millet has been observed for a number of agronomic traits, especially among the landraces (Wanyera, 2007). However, finger millet suffers from limited funding for research, lack of agronomic recommendations and changing farming systems that increase likelihoods of genetic erosion of finger millet. In certain regions, genetic diversity of finger millet has not yet been tapped for crop improvement in addition to remaining un-described, being poorly understood and under-utilized (Upadhyaya et al., 2008). Hence, collection and evaluation of available genetic diversity seems to be important for sustainable agriculture particularly in Central Himalayan Region. The present investigation was conducted with the objective to collect and evaluate finger millet germplasm available in Central Himalayan Region of India and to find out available variability in different pheno-physiological traits for further utilization.

\section{Materials and Methods}

A total of 314 accessions having unique traits of agronomic importance were collected from altitudinal range of $225-2250 \mathrm{~m}$ as in the Central Himalayan Region i.e., Uttarakhand state of India. These accessions have been evaluated with four checks (two local accessions i.e., Almora Local and Pithoragarh Local and two released varieties i.e., VL-146 and VL-149) preferred by the farming community across the region and occupying maximum area. Climate in Central Himalayan Region is characterized by vagaries of weather. Unpredictable extreme weather and climate events have the potential to upset the normal life processes of plants and cause great uncertainty in the assessment of production and productivity. The soil at experimental site is sandy loam with medium organic matter content and pebbles in plenty. Annual precipitation average over last 10 years has been $1200-1800 \mathrm{~mm}$. Temperature fluctuations during Kharif crop range from $10-25^{\circ} \mathrm{C}$.

Leaf length $(\mathrm{cm})$, leaf width $(\mathrm{cm})$, leaf angle (degree) of flag leaf as well as peduncle length has been measured at flowering stage. Days to harvest were counted and recorded at harvest. Plant height $(\mathrm{cm})$, ear length $(\mathrm{cm})$ and thousand seeds weight $(\mathrm{g})$ was recorded at harvest. Days to $50 \%$ flowering and days to $80 \%$ maturity was recorded when approximately $50 \%$ plants were at flowering and $80 \%$ plants were at yellowing/ senescing stage respectively. Chlorophyll (Strain et al., 1971) and carotenoids (Duxbury and Yentshe 1956) content were estimated in fresh leaf tissues at flowering stage. Lipid peroxidation was measured in terms of malondialdehyde (MDA) content following the standard procedure of Heath and Packer (1968). Total dietary fibre contents were determined by AOAC method (2005). Total carbohydrates content were estimated by the anthrone reagent method (Morris, 1948). Protein content were determined by folin ciocalteau reagent method (Lowry et al., 1951) and fat content by AOAC method (AOAC, 1998).

Experiments were conducted during Kharif season (June-October) in Augmented Block Design (ABD). Five representative plants of each accession were tagged in each block for recording observations. The statistical analysis for principal component was performed using statistical software SAS 9.3. Data for each parameter were evaluated for statistical significance using two-way analysis of variance (ANOVA) to compare the means considering accession and trait as independent variables. 


\section{Results and Discussion}

Genetic variation is a prerequisite for crop improvement. Environmental conditions during plant growth and development affect various morpho-physiological traits, flowering, fruiting behaviour and productivity (Trivedi et al., 2015a). Response of a crop to environmental conditions varies from genotype to genotype. Germplasm characterization is an important link between conservation and utilization of plant genetic resources in crop improvement programmes (Kaluthanthri and Dasanayaka, 2016).
Considerable diversity has been found in different traits under study i.e., approximately five fold variability was recorded in leaf length which varied from 17.91 to $97.92 \mathrm{~cm}$; leaf width ranged 0.83 to $1.23 \mathrm{~cm}$. More variability was found in leaf length as compared to leaf width, reason being in cereal crops, leaf blade expansion takes place via an increase in length than in width since their emergence from sheath bundle (Bos and Neuteboom, 1998). Flag leaf angle varied from $19^{\circ}-53^{\circ}$, this considerably affects light interception, photosynthesis and finally plant productivity. Peduncle length varied from 9.02 to $45.43 \mathrm{~cm}$. Similarly, plant height ranged from 71.71 to $140.30 \mathrm{~cm}$. Since

Table 1 : Genetic diversity in vegetative characters, flowering behaviour and yield of finger millet in Central Himalayan Region

\begin{tabular}{|c|c|c|c|c|c|c|c|}
\hline Trait & Minimum & Maximum & Best check value & Average & STDEV & SE & $\mathrm{CV} \%$ \\
\hline Flag leaf length (cm) & 17.91 & 97.92 & 52.20 & 29.32 & 5.100 & 2.190 & 17.65 \\
\hline Flag leaf width (cm) & 0.83 & 1.23 & 1.08 & 1.01 & 0.054 & 1.634 & 5.69 \\
\hline Flag leaf angle (degree) & 19.00 & 53.00 & 44.00 & 37.00 & 5.30 & 0.30 & 14.00 \\
\hline Peduncle length (cm) & 9.02 & 45.43 & 16.24 & 14.91 & 2.921 & 0.053 & 19.84 \\
\hline Plant height $(\mathrm{cm})$ & 71.71 & 140.30 & 135.00 & 115.29 & 10.311 & 0.821 & 9.26 \\
\hline Ear head length (cm) & 4.16 & 14.61 & 11.23 & 7.82 & 2.023 & 0.118 & 27.48 \\
\hline Days to $50 \%$ flowering & 66.00 & 98.00 & 86.00 & 77.33 & 6.521 & 0.351 & 8.30 \\
\hline Days to $80 \%$ maturity & 117.00 & 147.00 & 139.00 & 132.00 & 3.660 & 0.207 & 2.74 \\
\hline Days to harvesting & 141.00 & 149.00 & 149.00 & 144.80 & 2.10 & 0.10 & 1.47 \\
\hline 1000 seed weight $(\mathrm{g})$ & 1.01 & 4.71 & 3.40 & 2.61 & 0.631 & 0.033 & 24.33 \\
\hline
\end{tabular}

* Values presented in the table are representative value of 314 accessions.

(a)

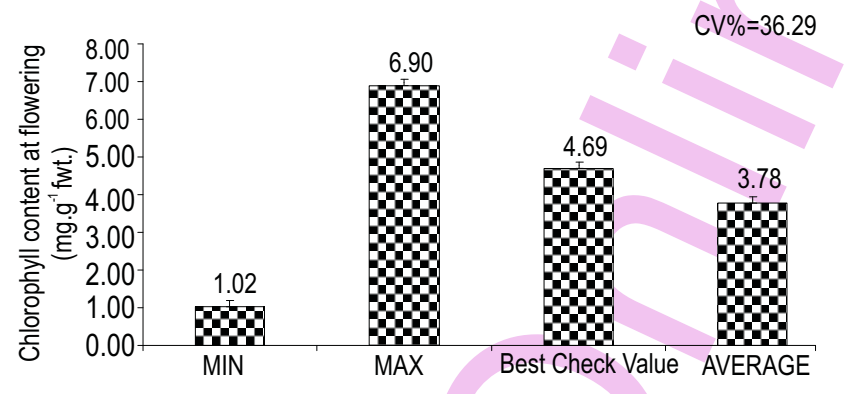

(c) (b)

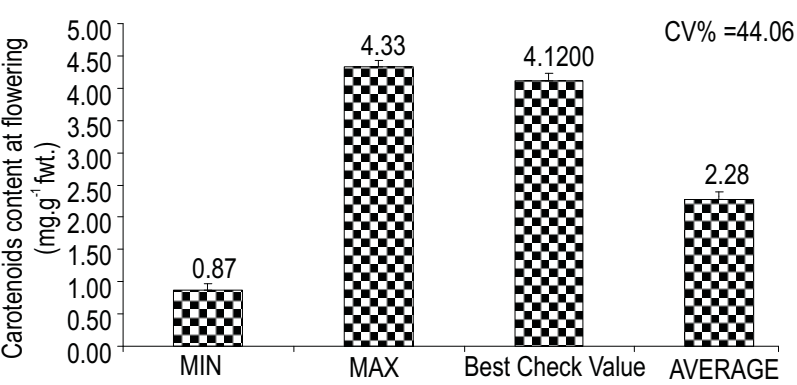

$\mathrm{CV} \%=47.95$

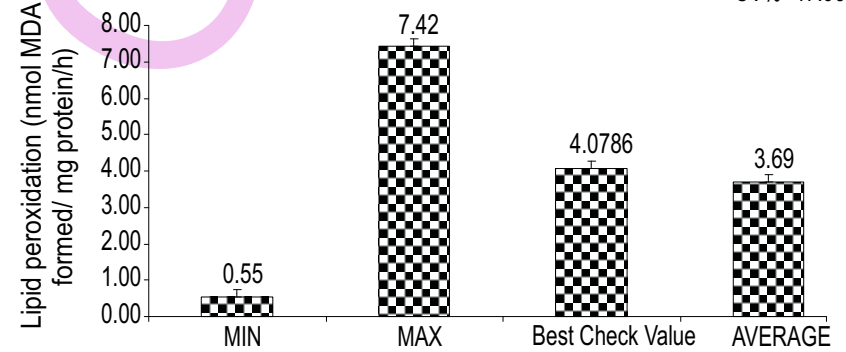

Fig. 1: Genetic variability in total chlorophyll, carotenoids content and lipid perxidation at flowering. * Values presented in the figure are representative value of 314 accessions 

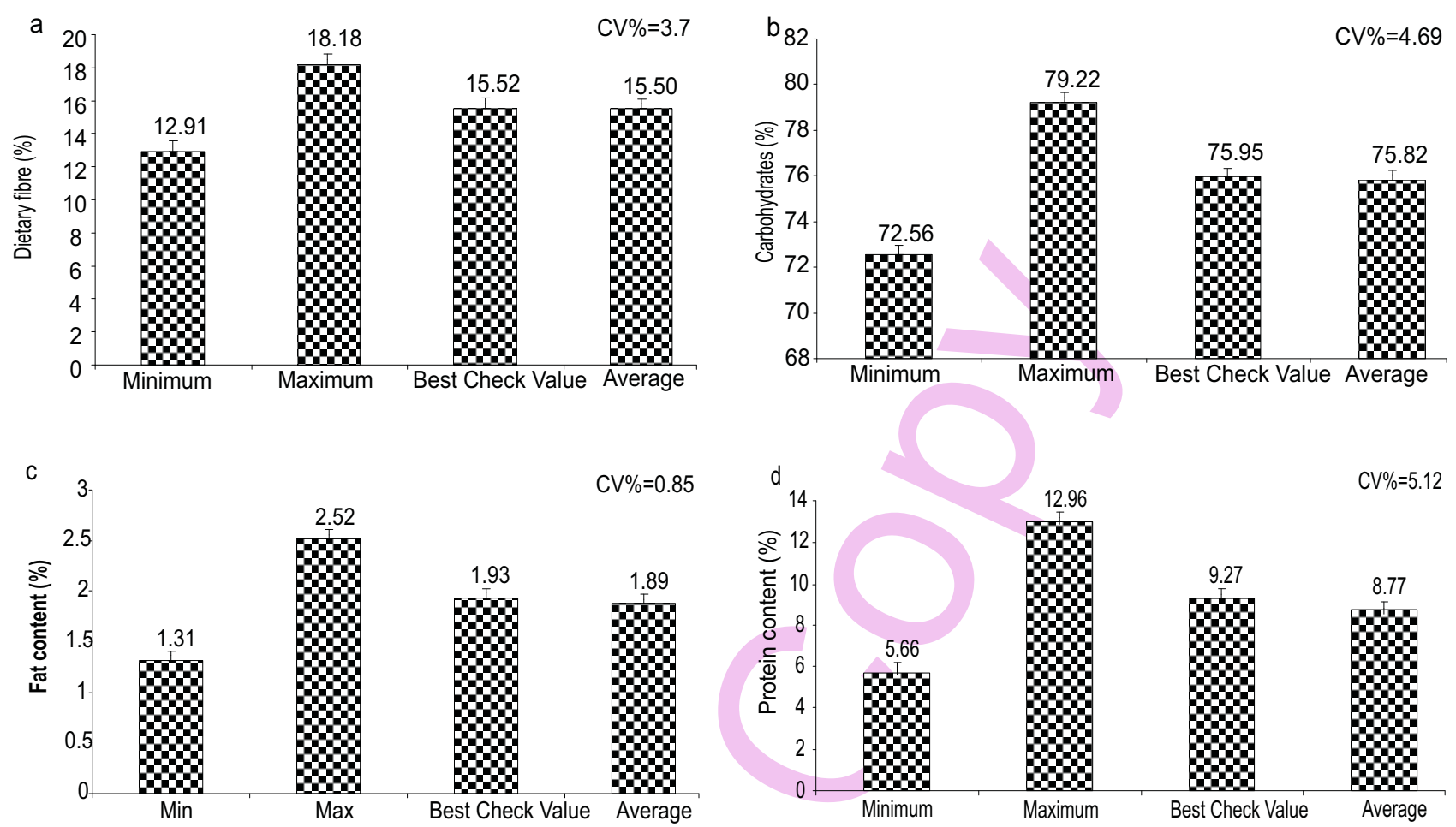

Fig. 2 : Genetic variability in dietary fibre, carbohydrate, fat and protein content in seed powder. * Values presented in the figure are representative value of 314 accessions

Table 2 : Principal components, eigen value, percent variance and contribution of the first four principal component axes to variation in finger millet based on phenol-physiological traits

\begin{tabular}{|c|c|c|c|c|c|c|}
\hline Principal component & Eigen value & $\%$ variance & PC 1 & PC 2 & PC 3 & PC 4 \\
\hline Flag leaf length $(\mathrm{cm})$ & 115.69100 & 46.1420 & 0.129 & 0.1298 & 0.247 & 0.9386 \\
\hline Flag leaf width (cm) & 50.80440 & 20.2630 & 0.0007407 & 0.0003747 & 0.001857 & 0.001999 \\
\hline Flag leaf angle (degree) & 28.68700 & 11.4410 & -0.005852 & -0.005812 & 0.958 & -0.2631 \\
\hline Peduncle length (cm) & 25.36050 & 10.1150 & 0.02754 & -0.06967 & -0.07689 & -0.01793 \\
\hline Plant height $(\mathrm{cm})$ & 9.02537 & 3.5996 & 0.9815 & -0.1224 & 0.01946 & -0.1122 \\
\hline Days to $50 \%$ flowering & 7.82979 & 3.1228 & 0.1023 & 0.898 & -0.074 & -0.1644 \\
\hline Days to $80 \%$ maturity & 3.89486 & 1.5534 & 0.03752 & 0.3932 & 0.08338 & 0.03399 \\
\hline Ear head length $(\mathrm{cm})$ & 3.47269 & 1.3850 & 0.08509 & -0.01602 & -0.003557 & 0.04278 \\
\hline Days to harvesting & 2.90471 & 1.1585 & 0.002929 & 0.03719 & -0.01039 & -0.07309 \\
\hline 1000 seed weight $(\mathrm{g})$ & 1.72551 & 0.6881 & -0.0002151 & -0.008255 & -0.002696 & -0.01203 \\
\hline Chlorophyll content (mg.g $\mathrm{g}^{-1} \mathrm{f}$ wt.) & 0.95577 & 0.3811 & -0.2684 & 0.01967 & -0.0238 & -0.03883 \\
\hline Carotenoids content (mg. $\mathrm{g}^{-1} \mathrm{f}$ wt.) & 0.37585 & 0.1499 & -0.006734 & -0.01178 & -0.007854 & 0.000108 \\
\hline $\begin{array}{l}\text { Lipid Peroxidation (nmol MDA formed. } \\
\mathrm{mg}^{-1} \text { protein. } h \mathrm{hr}^{-1} \text { ) }\end{array}$ & 0.00281 & 0.0011 & -0.9377 & 0.003403 & 0.04143 & 0.001575 \\
\hline
\end{tabular}

finger millet is grown as food, feed/ fodder and consumed by disadvantaged groups, plant height is an important trait for selection. Height is a decisive trait of a plants ability to compete for light and correlated with traits such as leaf mass per unit area and canopy area (Falster and Westoby, 2003). It is an important part of life-history traits including seed mass, time to reproduction, longevity and number of seeds a plant can produce per year (Moles and Leishman, 2008). These traits are crucial in determining how a species lives, grows and reproduces. Days to $50 \%$ flowering in different accessions have been found to vary 66 days to 98 days. Transition from vegetative to reproductive phase measured as days to $50 \%$ flowering is a critical developmental 
switch and a key adaptive trait which ensures that plants set their flowers at an optimum time for pollination, seed development and dispersal (Cockram et al., 2007). Considerable variation recorded in maturity time of different accessions (days to $80 \%$ maturity ranged from 117 to 147 days and days to harvesting ranged 141 to 149 days) indicates their potential for utilization in different agroclimatic conditions. Investigating genetic diversity and patterns of early-and late flowering landraces is very important since flowering cycles and photoperiod sensitivity play a crucial role in the adaptation to climatic conditions (Diack et al. 2017). There is a critical need for adapting local agriculture to harsher future conditions, landraces and improved varieties adaptation will mostly rely on standing genetic variation available within the cultivated compartment (Diack et al. 2017). Farmers as well as plant breeders have selected differences in flowering time to increase yield and extend the agricultural flexibility and ecogeographical range of crops (Cockram et al., 2007). Nevertheless, more than three fold diversity was recorded in ear head length which ranged from 4.16 to $14.61 \mathrm{~cm}$. Ear head length is an important trait of plant productivity, if seeds are set properly. Thousand seeds weight varied from 1.01 to $4.71 \mathrm{~g}$ (Table 1). Himalayan Region, at present, is facing the challenges created due to increasing aridity, warmer winter season, variability in precipitation and unexpected frosts and storms (Renton, 2009) which largely affect the entire range of biodiversity (Kala, 2013) and an increase in interest for germplasm suitable to changing conditions.

Chlorophyll content at flowering stage ranged 1.02 to 6.90 $\mathrm{mg} . \mathrm{g}^{-1}$ fresh tissues (Fig. 1a). Chlorophyll contents are of particular significance to agriculture as indicators of photosynthetic activity (Bojovic and Stojanovic, 2005). In plants, maximum chlorophyll content occurs at the outset of the flowering phase and chlorophyll is believed to take part in the process of organoganesis (Simova-Stoilova et al., 2001), hence estimation of chlorophyll at flowering stage may give better relative values of the photosynthetic activity of germplasm. Carotenoids content ranged 0.87 to $4.33 \mathrm{mg} . \mathrm{g}^{-1}$ fresh wt. (Fig. 1b). Carotenoids have two important functions in plants. First, they contribute to photosynthesis by transferring some of the light energy they absorb to chlorophylls. Chlorophylls use this energy to drive photosynthesis. Second, they protect plants which are overexposed to sunlight, by harmlessly dissipating excess light energy, which they absorb, as heat. Hence, these are useful for stress tolerance. Ample variability in lipid peroxidation has been found in collected germplasm which varied 0.55 to $7.42 \mathrm{nmol}$ MDA formed $\mathrm{mg}^{-1}$ protein $\mathrm{h}^{-1}$ (Fig. 1c). Lipid peroxidation is an indicator of oxidative stress (Jagtap and Bhargava 1995). It is most easily ascribed symptom of oxidative damage (Zhang and Kirkham, 1996). Variability in this trait may be utilized to screen the germplasm for stress tolerance.

Ultimately, seed quality traits are main criteria for selection of a crop to be grown in a region on large scale. From the study, it is evident that substantial diversity of seed quality traits is available in the germplasm viz., dietary fibers in powdered seeds varied from 12.91 to $18.18 \%$ (Fig. 2a), carbohydrates content
72.56 to $79.22 \%$ (Fig. 2b), fat content 1.31 to $2.52 \%$ (Fig. 2c) and protein content 5.66 to $12.96 \%$ (Fig. 2d). Available finger millet diversity has a vast scope for supporting the commercially grown crops by reducing pressure on their availability, cheap source of nutrients as well as it can be raised at low management cost (Sankhala etal., 2004).

Principal components and percentage contribution of each component to total variation is shown in Table 2. First four variables contribute $87.96 \%$ of total variability. First component accounted for $46.14 \%$ of total variation and contained four main traits corresponding to plant height $(0.9815)$, flag leaf length $(0.129)$, days to $50 \%$ flowering (0.1023), ear head length (0.08509). Second principal component contributed $20.26 \%$ of total variability; four main traits responsible for positive contribution were days to $50 \%$ flowering (0.898), days to $80 \%$ maturity, flag leaf length $(0.1298)$ and days to harvesting (0.03719). Similarly, flag leaf angle (0.958), flag leaf length $(0.247)$, days to $80 \%$ maturity $(0.08338)$ and lipid peroxidation $(0.04143)$ were the highest contributing traits to third principal component which accounted for 11.44 percent of total variation. Fourth component contributed $10.11 \%$ of total variation having flag leaf length (0.9386), ear head length (0.04278), days to $80 \%$ maturity (0.03399) and flag leaf width (0.001999) as the highest positive contributors. It is evident that only four principal components contributed considerably towards diversity. Plants perceive environmental signals which affect plant processes (Soares-Cordeiro et al., 2010) in turn difference in effect on plant processes is pivotal for diversity. The understanding of plant responses to environmental conditions is crucial for plant behaviour in climate change perspective (Trivedi et al., 2015b).

Collection and evaluation of germplasm may be used as a strategy to identify trait specific germplasm. The results reveal considerable diversity in finger millet germplasm of Central Himalayan Region that can be utilized for tailoring climate resilient varieties and selection of germplasm for cultivation in different agro-climatic conditions/ zones. A wide gene pool with known pheno-physiological traits might be a boon for continued improvement of crops through breeding as well as for food security.

\section{Acknowledgments}

Authors are thankful to the Director, ICAR - National Bureau of Plant Genetic Resources, Pusa Campus, New Delhi for providing necessary facility and keen interest in the study. Authors are thankful to the research expertise of the Journal of Environmental Biology also for critical comments to technically improve the manuscript.

\section{References}

Association of Official Analytical Chemists: AOAC Official Methods 2001.03 Dietary fiber in foods containing resistant maltodextrin. In: Official methods of analysis of the Association of Official Analytical Chemists. $14^{\text {th }}$ Edn., Association of Official Agricultural Chemists, Washington, DC (2005). 
Association of Official Analytical Chemists: Methods 996.01 Fats (total, saturated, unsaturated and monounsaturated) in cereal products, in AOAC Official Methods of Analysis, $17^{\text {th }}$ Edn., Association of Official Agricultural Chemists, Arlington, VA(1998).

Bojovic, B. and J. Stojanovic: Chlorophyll and carotenoid content in wheat cultivars as a function of mineral nutrition. Arch. Biol. Sci., Belgrade, 57, 283-290 (2005).

Bos, H. J. and J. H. Neuteboom: Growth of individual leaves of spring wheat (Triticum aestivum L.) as influenced by temperature and light intensity. Ann. Bot., 81, 141-149(1998).

Cockram, J., H. Jones, F. J. O. Leigh, D. Sullivan, W. Powell, D. A. Laurie and A. J. Greenland: Control of flowering time in temperate cereals: genes domestication and sustainable productivity. J. Exp. Bot., 58, 1231-1244 (2007).

Das, S., R. C. Mishra, G. R. Rout and S. Aparajita : Genetic variability and relationships among thirty genotypes of finger millet (Eleusine coracana L. Gaertn.) using RAPD markers. J. Biosci., 62, 116 122 (2007).

Diack, O., N. D. Kane, C. B. Salazar, M. C. Gueye, B. M. Diop, A. Fofana, O. Sy, H. Tall, L. Zekraoui, M. Piquet, M. Couderc, Y. Vigouroux, D. Diouf and A. Barnaud: New Genetic Insights into pearl millet diversity as revealed by characterization of early-and lateflowering landraces from Senegal. Front. Plant Sci., 8, 818 (2017).

Dida, M. M. and K. M. Devos: Finger millet. In: Genome Mapping and Molecular Breeding in Plants (Ed.: K. Chittarajan, K.). SpringerVerlag, 1, 333-344 (2006).

Duxbury, A. C. and C. S. Yentshe: Plankton pigment monographs. J. Marine Res., 15, 19-101 (1956).

Falster, D. S. and M. Westoby. Plant height and evolutionary games. Trends in Ecol. Evol., 18, 337-343 (2003).

FAO: Grassland Index. A searchable catalogue of grass and forage legumes. FAO, Rome, Italy (2012).

Govind, G., V. Harshavardhan, J. K. Patricia, R. Dhanalakshmi and M. Senthil Kumar : Identification and functional validation of a unique set of drought induced genes preferentially expressed in response to gradual water stress in peanut. Mol. Genet. Genomics, 281, 591 -605 (2009).

Heath, R. L. and K. Packer : Leaf senescence: Correlated with increased levels of membrane permeability and lipid peroxidation and decreased levels of superoxide dismutase and catalase. J. Exp. Bot., 32, 93-101 (1968).

Hilu, K. W. : Evolution of finger millet: evidence from random amplified polymorphic DNA. Genome, 38, 232-238 (1995).

ICRISAT. ICRISAT/Gene bank activities; www.icrisat.org/genebank (2008).

Jagtap, V. and S. Bhargava : Variation in the antioxidant metabolism of drought tolerant and drought susceptible varieties of Sorghum bicolor (L.) Moench. exposed to high light, low water and high temperature stress. J. Plant Physiol., 145, 195-197 (1995).

Kala, C.P.: Climate change and challenges of biodiversity conservation. In: Biodiversity, Communities and Climate Change (Eds.: Kala, C.P. and Silori C.S.) New Delhi: The Energy and Resources Institute, pp. 259-269 (2013).

Kaluthanthri, D.V.S. and P.N. Dasanayaka : Assessment of genetic diversity of some finger millet (Eleusine coracana (L.) Gaertn. accessions using morphological markers. J. Trop. Forest. Environ., 6, 25-35 (2016).

Lowry, O. H., N. J. Rosenbrough, L. Farr and J. Randall : Protein measurement with the folin-phenol reagent. J.Biol. Chem., 193, $265-275(1951)$.
Moles, A. T. and M. R. Leishman: The seedling as part of a plant's life history strategy. In: Seedling Ecology and Evolution (Eds.: M. A. Leck, V. T. Parker and R. L. Simpson). Cambridge University Press, Cambridge, pp. 217-238 (2008).

Morris, D. L. : Quantitative determination of carbohydrates with Dreywood's anthrone reagent. Science, 107, 254-255(1948).

Quarrie, S.A., J. Stojanović and S. Pekić: Improving drought resistance in small grained cereals : A case study, progress and prospects. Plant Growth Regul., 29, 1-21 (1999).

Renton, A.: Suffering the science: climate change, people and poverty. Oxfam briefing paper number 130. Oxford: Oxfam International. (2009).

Richards, R.A.: Crop improvement for temperate Australia : future opportunities. Field Crop Res, 26, 141-169 (1991).

Sankhala, A., S. Chopra and A. K. Sankhala: Effect of processing on tannin, phytate and in vitro iron in underutilized millets- Bajra (Pennisetum typhoideum) and Kangni (Setaria italica). Indian J. Nutr. Dietet., 41, 55-62(2004).

Simova-Stoilova, Lj., Z. Stoyanova and K. Demirevska-Kepova : Ontogenic changes in leaf pigments, total soluble protein and Rubisco in two barley varieties in relation to yield. Bulg. J. Plant Physiol., 27, 15-24 (2001).

Soares-Cordeio, A. S., S. P. Driscoll, M. C. Arrabac and C.H. Foyer: Dorsoventral variations in dark chilling effects on photosynthesis and stomatal function in Paspalum dilatatum leaves. J. Exp. Bot., 62, 687-699 (2010).

Strain, H. H., T. C. Bengamin and A. S. Walter : Analytical procedure for isolation, identification, estimation, investigation of chlorophyll. In: Methods in Enzymology (Ed.: A. S. Pietro). New York: Academic Press, pp. 423-452(1971).

Takan, J. P., J. Chipili, S. Muthumeenakshi, N. J. Talbot, E. O. Manyasa, R. Bandyopadhyay, Y. Sere, S. K. Nutsugah, P. Talhinhas, M. Hossain, A. E. Brown and S. S. Prasad: Magnaporthe oryzae populations adapted to finger millet and rice exhibit distinctive patterns of genetic diversity, sexuality and host interaction. Mol. Biotech., 50, 145-158 (2012).

Tardieu, F. and R. Tuberosa: Dissection and modelling of abiotic stress tolerance in plants. Curr. Opin. Plant Biol., 13, 206-212 (2010).

Trivedi, A. K., S. K. Verma, R. R. Arya and R. K. Tyagi: Genetic diversity in antioxidant potential and stomatal behaviour of peach in Central Himalayan Region. J. Environ. Biol., 36, e669 - e675 (2015b).

Trivedi, A. K., S. K. Verma, R. R. Arya and R. K. Tyagi: Variability in morpho-physiological traits and antioxidant potential of kiwifruit (Actinidia chinensis Planch) in Central Himalayan Region. J. Environ. Biol., 36, 1051 - 1056 (2015a).

Upadhyaya, H. D., R. P. S. Pundir, C. L. L. Gowda, V. G. Reddy and S. Singh. Establishing a core collection of foxtail millet to enhance utilization of germplasm of an underutilized crop. Plant Genet. Resour. : Charact.Utiliza., 7, 177-184 (2008).

Wanyera, N. M. W.: Finger millet (Eleusine coracana (L) Gaertn) in Uganda. In : Proceedings of the First International Finger Millet Stake-Holders Workshop (Eds.: Mgonja, M. A., J. M. Lenne, E. Manyasa, and S. S. Prasad), pp. 1-9 (2007).

Werth, C. R., K. W. Hilu and C. A. Langner. Isozymes of Eleusine (Gramineae) and the origin of finger millet. Am. J. Bot., 81, $1186-$ 1197 (1994).

Zhang, J. and M. B. Kirkham. Lipid peroxidation in sorghum and sunflower seedlings as affected by ascorbic acid, benzoic acid, and propyl gallate. J. Plant Physiol., 149, 489-493 (1996). 